\title{
Optical coherence tomography on autologous translocation of choroid and retinal pigment epithelium in age-related macular degeneration
}

${ }^{1}$ Department of

Vitreoretinal Surgery, Center for Ophthalmology, University of Cologne,

Cologne, Germany

${ }^{2}$ Department of Ophthalmology, University of Duesseldorf, Duesseldorf, Germany

${ }^{3}$ Koordinierungszentrum Klinische Studien (KKSK), University of Cologne, Cologne, Germany

Correspondence:

AM Joussen,

Department of

Ophthalmology,

University of Duesseldorf, Moorenstr. 5,

Duesseldorf 40225,

Germany

Tel: +49 21181 17320;

Fax: + 492118116342

E-mail: Joussena@

googlemail.com

Received: 25 May 2006 Accepted in revised form: 12 December 2006

Published online: 2 March 2007

Proprietary interest: none for all authors

\begin{abstract}
Purpose To analyse structural changes after autologous translocation of choroid and retinal pigment epithelium (RPE) in patients with age-related macular degeneration (AMD) using optical coherence tomography (OCT). Methods We performed a prospective nonrandomised study in 29 consecutive patients, who underwent submacular surgery with translocation of an autologous fullthickness graft of RPE, Bruch's membrane, and choroid. All patients had recent loss of reading vision due to AMD. OCT was performed before surgery and at 3- and 6- month follow-up to analyse the morphological appearance of the graft and the overlying retina. Results Maximum retinal thickness decreased from mean $408 \mu \mathrm{m}$ (standard deviation (SD) $127 \mu \mathrm{m}$ ) preoperative to mean $373 \mu \mathrm{m}$ (SD $104 \mu \mathrm{m})$ at 6-month follow-up ( $P=0.094)$. In 11 cases (40\%), a nearly physiological shape of the retina was seen at this time point. A macular hole persisted in two eyes after silicone oil removal. In most eyes, the highly reflective band of the graft presumably corresponding to RPE was continuous with the surrounding RPE band in all six OCT scans. Eyes with flat appearance of the graft at 6-month follow-up $(<300 \mu \mathrm{m})$ showed a significantly better functional outcome than eyes with more prominent grafts. Interestingly, most patients did not complain about metamorphopsia, even though the graft was prominent or wrinkled in some cases.

Conclusion OCT is a useful tool in monitoring intra- and subretinal changes after
\end{abstract}

S Joeres ${ }^{1}$, H Llacer ${ }^{1,2}$, FMA Heussen ${ }^{1}$, C Weiss ${ }^{3}$, B Kirchhof ${ }^{1}$ and AM Joussen ${ }^{1,2}$ subretinal surgery with graft translocation. We demonstrated that graft translocation may lead to a normalisation of retinal thickness and stabilisation of visual acuity.

Eye (2008) 22, 782-789; doi:10.1038/sj.eye.6702761; published online 2 March 2007

Keywords: OCT; age-related macular degeneration; submacular surgery; graft; translocation

Introduction

Age-related macular degeneration (AMD) is the most common cause of severe visual acuity loss in individuals 65 years of age or older. ${ }^{1}$

Neovascular AMD is responsible for over $80 \%$ of severe visual loss due to $\mathrm{AMD},{ }^{2}$ whereas the dry form of AMD comprises about $90 \%$ of all cases. Visual loss related to neovascular AMD is, at least in part, related to vascular leakage resulting in macular thickening.

Photodynamic therapy (PDT) and antivascular endothelial growth factor (VEGF) therapies have been shown to slow the course of the disease in subtypes of wet AMD. ${ }^{2-5}$ Simple surgical removal of the membrane did not result in improvement of visual acuity, ${ }^{6}$ and attempts to transplant suspensions of retinal pigment epithelial (RPE) cells resulted in a temporary improvement but did not result in a long-term functional monolayer..$^{7}$ After $360^{\circ}$ macular translocation, late macular oedema, as well as rapid recurrence of geographic atrophy have been documented. ${ }^{8-12}$ 
Peripheral autologous translocation of the choroid is a novel approach to stabilise visual acuity. ${ }^{13-15}$ In this surgery, a full thickness graft of choroid, Bruch's membrane, and RPE is taken from the midperipheral fundus and positioned under the macula. The reaction of the retinal tissue to the transplanted graft and the interaction between retina, RPE, and choroids, however, are not yet fully understood. Funduscopy and angiography allow only limited assessment of epi-, intra-, and subretinal changes. Fukuchi et al ${ }^{16}$ and Toth et $a l^{17}$ have demonstrated that the pseudo-color banding of retinal optical coherence tomography (OCT) images correlate well with histology. Contemporary literature is focusing on the detection of intra- or subretinal fluid, ${ }^{18-20}$ vitreo-macular traction, ${ }^{21}$ or macular hole formation.

In our study, we performed OCT imaging to analyse the epi-, intra-, and subretinal changes after translocation of autologous RPE and choroid.

\section{Methods}

\section{Patients and surgical treatment}

Included into this analysis were 29 patients recruited within the 'patch-study' (peripheral autologous translocation of the choroid), ${ }^{13,14}$ who were examined by OCT preoperatively and 3 and 6 months postoperatively (complete cases). Sixteen patients were female, 13 were male. All patients presented with a loss of vision due to AMD. Surgery was performed owing to classic membrane in two cases, occult membrane in eight cases, vascularised pigment epithelium detachment in 10 cases, rip of pigment epithelium in one eye, massive subretinal bleeding in three eyes, and geographic atrophy in five cases. The target group of patients were those with large subfoveal lesions ( $>5$ papillary diameter) or poorly demarcated lesions to which laser photocoagulation or PDT was judged to be inappropriate. Similarly, classic lesions that failed to improve after the first PDT and patients seeking alternative treatment options were included in the study because of patient's preference after discussion of pharmacological and surgical options.

Translocation surgery is described elsewhere. ${ }^{13,14}$ In short, a present subretinal membrane was excised via a central retinotomy medial within the arcade region after standard pars plana vitrectomy. An area of about 5-6 disc areas was demarcated and excised in the mid periphery. The graft consisting of intact RPE, Bruch's membrane, and the underlying choroid was positioned underneath the macula. In eyes with dry AMD, Bruch's membrane was incidentally damaged to allow for vascularisation of the graft. As vitreous tamponade either SF6 20\% (first four eyes), silicone oil (5000 cst, 11 eyes), or heavy silicone oil (Densiron ${ }^{\circledR}$, Fluoron $\mathrm{GmbH}$, Neu-Ulm, Germany, last 14 eyes) was used. The surgeon used different endotamponades throughout the study to enhance mechanical protection against peripheral PVR that was developed in some patients to avoid PVR retinal detachments. Heavy silicone oil was chosen in patients with inferior excision areas of the graft. After a minimum of 3 months silicone oil was removed.

\section{Assessment of macular thickness and the graft by OCT}

OCT was performed with Carl Zeiss Meditec Model 3000, OCT3 system equipped with software version 4.0 (Zeiss-Humphrey, Zeiss Oberkochem, Germany).

The 'Fast Macular Thickness' acquisition protocol was used to acquire six $6 \mathrm{~mm}$ line scans. In addition, cross hair scans (horizontal and vertical $6 \mathrm{~mm}$ scans with $512 \mathrm{~A}$ scans per B scan for higher resolution) were performed to obtain better quality of the scans. Scans for evaluation were carefully selected to avoid errors in images due to movements of the patient's eye.

If the patients were unable to detect the intersection of the red scan lines because of low visual acuity or if they fixated eccentrically, they were asked to look straight forward and the scan lines were manually positioned over the graft.

In all eyes, maximum retinal thickness of the macula was measured using the computer algorithm provided by the Stratus OCT software, which determines the inner and outer retinal boundaries. If the computer did not identify the boundaries correctly, thickness

measurements were performed by manual positioning of the callipers.

In addition, in eyes with central fixation on the graft, retinal thickness was measured at the point of fixation (also if this was not in the fovea) in all of the six scans and the mean value was used for correlation with visual acuity.

The morphological appearance of the retina and the graft was analysed in all eyes by two independent examiners using the 'scan selection' mode providing non-aligned images. The retina covering the graft was classified into five groups: (1) macular oedema, (2) atrophy, (3) 'mixed' appearance with atrophic and oedematous areas, (4) normal retinal appearance, and (5) macular hole (Figure 1). Macular oedema was defined as retinal thickness of more than $250 \mu \mathrm{m}$ in contrast to atrophy with a retinal thickness below $150 \mu \mathrm{m}$ throughout the scan.

Furthermore, the appearance of the graft was described either as flat $(0-300 \mu \mathrm{m})$, prominent (300-500 $\mu \mathrm{m})$, or very prominent ( $>500 \mu \mathrm{m}$ ). Thickness of the graft was measured using commercially available software (Adobe Photoshop). The highly reflective band 

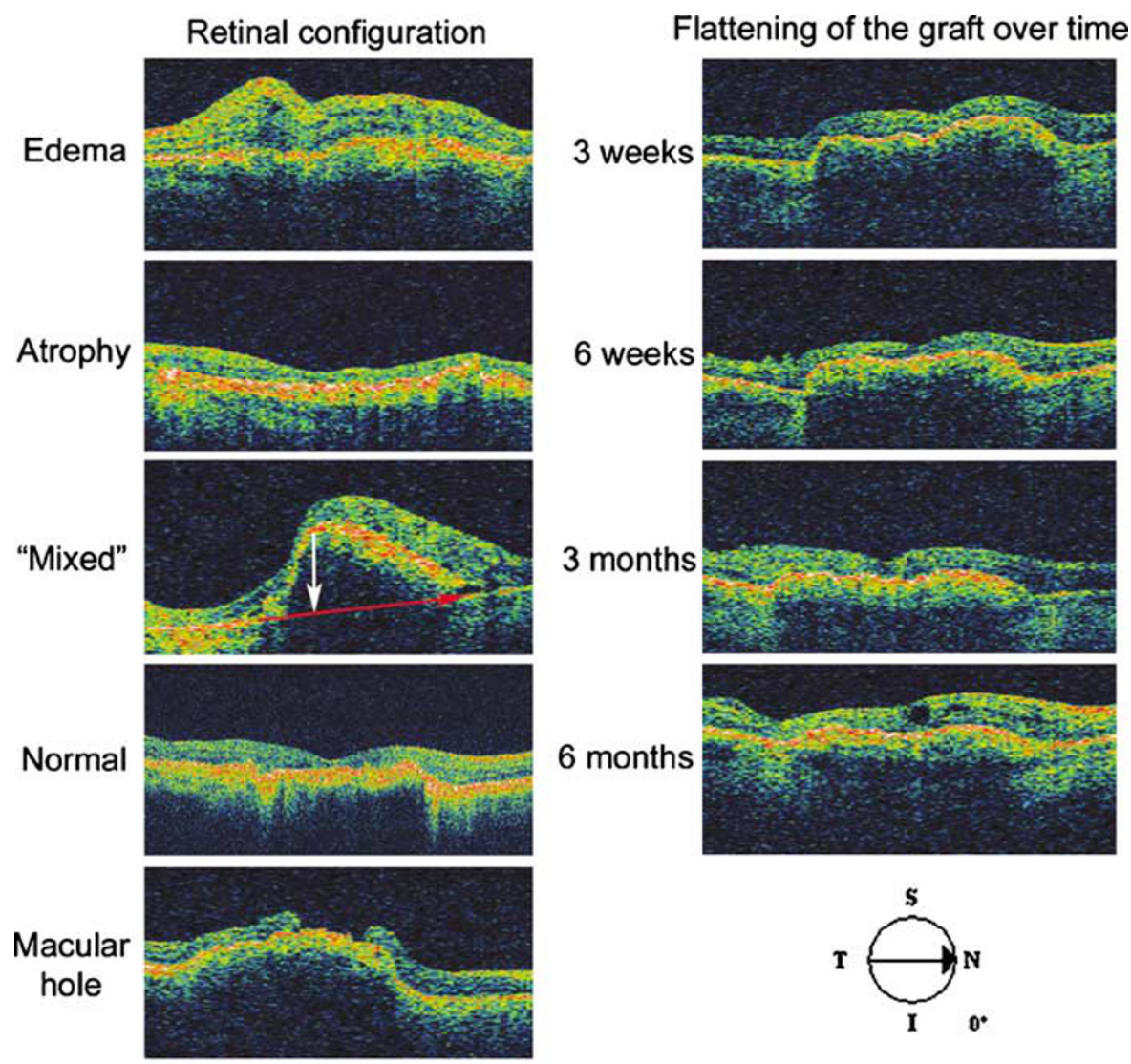

Figure 1 Retinal appearance after graft translocation: oedema, atrophy, mixed appearance, normal configuration, and macular hole. Thickness of the graft is defined as the maximum height (white arrow) from the 'normal position' of the RPE (red arrow) to the RPE of the graft (measurement demonstrated in a case with mixed appearance of the retina). Most grafts appeared prominent early after surgery, flattened within the first postoperative weeks and stayed flat during follow-up.

seen on the elevated area of the scan assumedly resembles the RPE layer of the graft. We chose the outer borders of the graft to be the normal position of the RPE band, which means the guessed line between clearly identifiable, surrounding RPE. Thickness of the graft was then defined as the maximum height from the normal position of the RPE to the RPE of the graft (Figure 1, red and white arrow).

\section{Visual acuity testing}

Best-corrected visual acuity testing was performed after full subjective ETDRS protocol refraction preoperatively and at each follow-up visit (logMAR) ${ }^{13}$ Reading performance was measured by a standardised reading test according to Radner et al. ${ }^{22,23}$ Reading acuity was calculated using a $\log \mathrm{RAD}$ value.

\section{Data analysis and statistical methods}

Statistical analysis was carried out using SAS (The SAS System, Release 9.1. 3 SP2; SAS Institute Inc., Cary, NC,
USA). Values are given as means and standard deviation (SD). Pearson correlation coefficients were calculated with analyse interrelation between visual acuity and retinal thickness (eligible only for patients with central fixation on the graft). Evaluation of the time effects (difference between 6-months and preoperative values) was performed using paired $t$-tests.

\section{Results}

\section{Morphology of the graft}

OCT examination was performed 6 weeks after surgery in 21 of 29 eyes, when the thickness of the graft measured $371 \mu \mathrm{m}$ (SD $192 \mu \mathrm{m}$ ), with nine of 21 grafts demonstrating a thickness of $>300 \mu \mathrm{m}$. Flattening of the graft occurred in 16 out of 27 patients during the follow-up (Figure 1), usually seen from 3 months onwards after surgery. After 6 months, average thickness of the graft was $332 \mu \mathrm{m}$ (SD $186 \mu \mathrm{m}$ ) with a moderate correlation to far vision ( $r=0.46, P=0.01)$ but no correlation to reading vision $(r=-0.19, P=0.52)$. Eyes with a flat graft $(<300 \mu \mathrm{m}$, 
$n=18$ ) at 6-month follow-up had the best mean distant visual acuity followed by those with prominent (300-500 $\mu \mathrm{m}, n=8)$ grafts. Eyes with very prominent grafts $(>500 \mu \mathrm{m})$ had the worst mean visual acuity $(n=3)$ (Figure 2).

Although the highly reflective band of the graft presumably corresponding to RPE was mostly attached to the hyper-reflective band of the recipient RPE in all six scans, in four cases each one of the six OCT scans intersect an area in which the edge of the graft seems to be not continuous with the surrounding RPE band or in

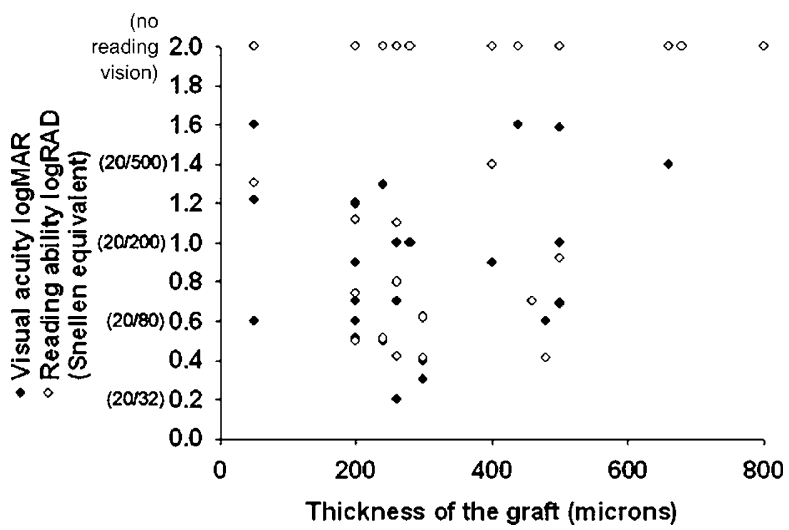

Figure 2 Scatter plot showing the correlation between visual acuity and thickness of the graft. Eyes with a flat appearance of the graft had a tendiously better far visual acuity than eyes with prominent or very prominent grafts (not statistically significant). ๑, distant visual acuity; $\bigcirc$, reading ability. which the margin of the graft was wrapped (Figure 3a and $b$ ). In selected patients, we saw a hypo-reflective window towards the choroid and the presence of two highly reflective bands of the graft (Figure $3 c-f$ ).

Few grafts had an uneven surface. The cavities of these uneven grafts were filled with retinal tissue, resulting in a straighter surface of the overlaying retina (Figure 3a and $b$ ). Most of these patients did not complain about distortion in their daily life, even though the graft surface was wrinkled. In eyes with central fixation and visual acuity better than $1.6 \log$ MAR (19 out of 29 eyes) only two patients complained about disturbing metamorphopsia. In both eyes the graft was flat, but one eye showed a macular hole and one demonstrated a fibrosis close to the point of fixation. A total of four patients reported a reduction of metamorphopsia after graft translocation.

\section{Retinal morphology and function}

Maximum retinal thickness in all eyes ranged from 179 to $681 \mu \mathrm{m}$ (mean $408 \mu \mathrm{m}, \mathrm{SD} 127 \mu \mathrm{m}, n=29$ ) preoperative and from 191 to $700 \mu \mathrm{m}$ (mean $373 \mu \mathrm{m}$, SD $104 \mu \mathrm{m}, n=29$ ) at the 6-month follow-up. Decrease in maximum retinal thickness from baseline to 6-months examination showed a tendency; however, this was not statistically significant $(P=0.1768)$. Mean visual acuity was $0.8 \log$ MAR

(SD 0.34 logMAR) preoperatively and $1.01 \log$ MAR

(SD $0.52 \log M A R)$ at 6 months. There was no relevant
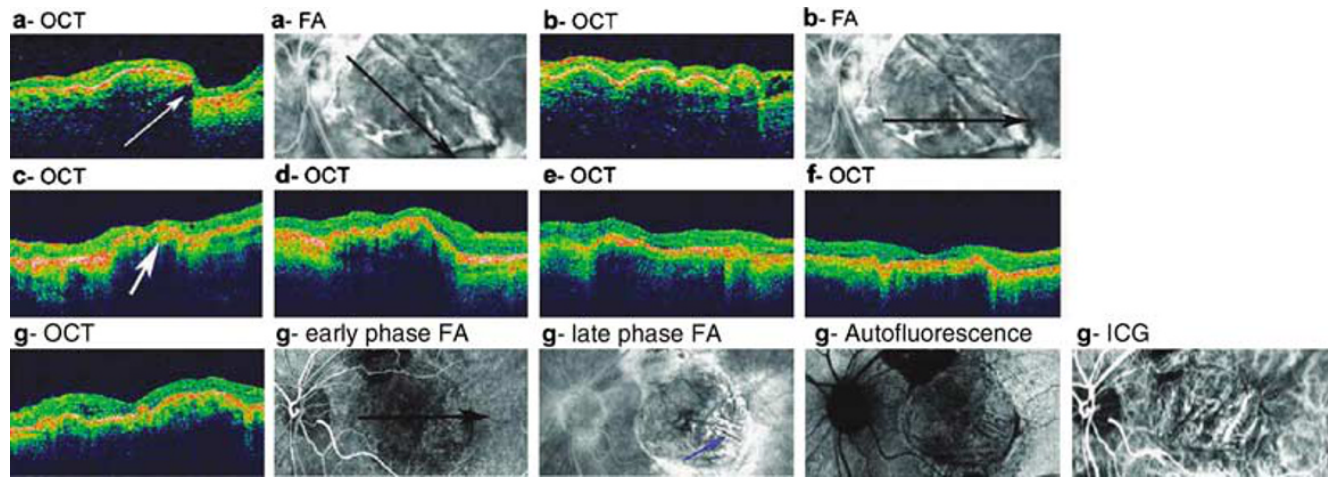

Figure 3 In some eyes the margin of the graft was wrapped and the RPE seemed to be not continuous with the surrounding RPE (white arrow in (a) OCT). Fluorescein angiography (FA) did not show signs for recurrence of CNV in this area (a) FA. The black arrow marks the position of the OCT scan). Some grafts appeared wrinkled (b) OCT). Nevertheless, most of these patients did not complain about metamorphopsia. The cavities of the graft are filled with retinal tissue, so that the overlaying retina appears straighter (black arrow in panel b-FA mark the position of the OCT scan). In some eyes, two bands of high reflectivity are present (c-f). Although the upper band is likely to be corresponding to RPE, the origin of the lower band (white arrow in panel c) is unknown. We presume that this line might represent choroidal vessels underneath the RPE of the graft. Case (g) presents with a foveal depression on OCT 6 months postoperative. Nasal from the fovea, a cystoid space is visible whereas in temporal the retina appears normal ((g) OCT, the black arrow in panel g - early phase FA marks the position of the OCT scan), autofluorescence is intact ((g) autofluorescence) and the graft is vascularised ( $\mathrm{g}$ ) ICG angiography). Fluorescein angiography shows a hyperfluorescence in the temporal half side of the graft in mid- and late phase of fluorescein angiography. Hypofluorescent lines were visible in the area of the graft (blue arrow in panel g-late phase FA). 
correlation between retinal thickness measured at the point of fixation (preoperative mean $290 \mu \mathrm{m}$, SD $129 \mu \mathrm{m}$, $n=15$; at 6-month follow-up mean $203 \mu \mathrm{m}$, SD $82 \mu \mathrm{m}$, $n=12$ ) and visual acuity.

Retinal morphology was further classified into five subgroups according to the presentation upon OCT analysis (Figure 1). Preoperatively 14 eyes presented with macular oedema, one eye with a retinal atrophy and 14 eyes with a normal appearance of the central retina (Table 1). At 6-month follow-up, central retinal oedema was seen in six eyes, with six more demonstrating a variable retinal thickness over the graft (mixed group).

Thirteen cases showed an improvement or stabilisation in visual acuity postoperative. In seven (54\%) out of these cases, a normal retinal configuration was seen at 6-month follow-up. In three eyes, visual acuity decreased during follow-up in the presence of a normal appearing retina.

In one eye with geographic atrophy, Bruch's membrane was not damaged during surgery.

Postoperative vascularisation of the graft appeared

Table 1 Morphology of the Retina 6 months postoperatively

\begin{tabular}{lcccc}
\hline 6 months preoperative & $\begin{array}{c}\text { Macular } \\
\text { oedema (6) }\end{array}$ & Atrophy (4) & $\begin{array}{c}\text { Mixed } \\
\text { appearance (6) }\end{array}$ & $\begin{array}{c}\text { Nacular } \\
\text { hole (2) }\end{array}$ \\
\hline Macular edema (14) & 3 & 2 & 4 & 4 \\
Atrophy (1) & 1 & 0 & 0 & 0 \\
Normal configuration (14) & 2 & 2 & 2 & 7 \\
\hline
\end{tabular}

Preop

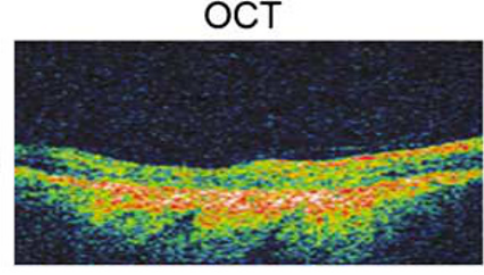

3 weeks

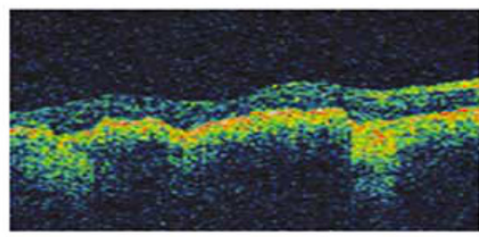

6 weeks

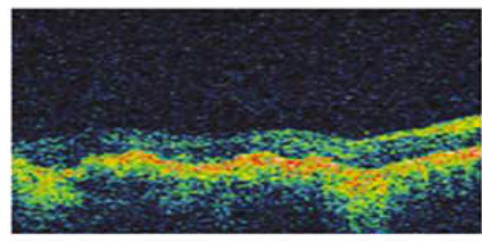

3 months

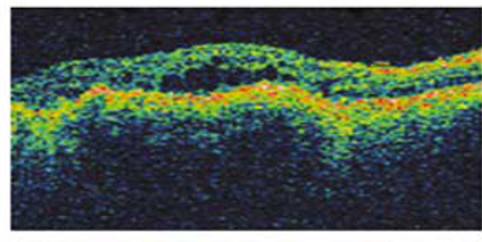

6 months

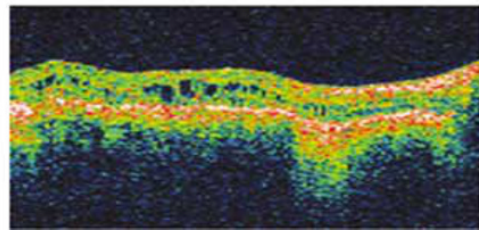

ICG
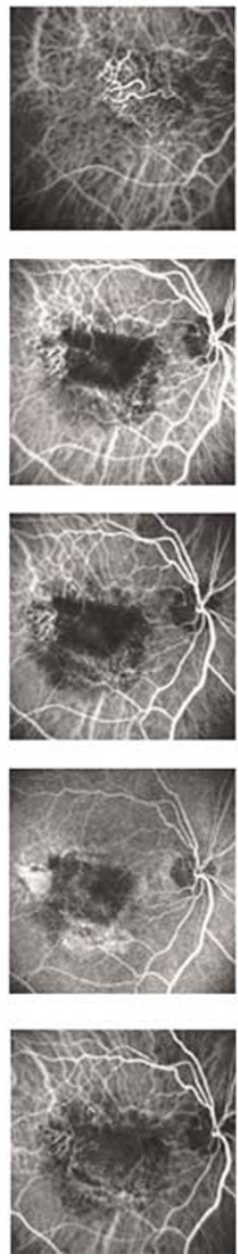

\section{Fluorescein}
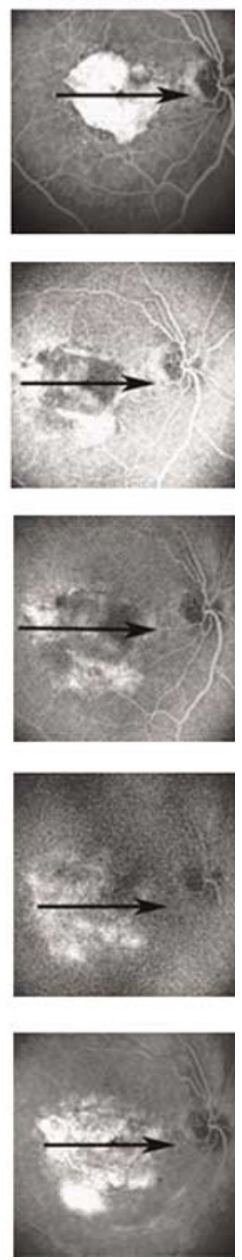

Figure 4 Patient with preoperative geographic atrophy. Three weeks postoperative, no vascularisation of the graft was seen on ICG angiography. Three months later, vascularisation slowly appeared associated with macular oedema, seen on OCT and fluorescein angiography. The black arrow marks the OCT scan. 
delayed on ICG angiography associated with macular oedema (Figure 4). In all patients with postoperative macular oedema or mixed appearance of the retina, angiography confirmed late hyperfluorescence. In seven eyes without signs of macular oedema on OCT, fluorescein angiography demonstrated hyperfluorescence in the area of the graft in mid and late phase (Figure 3g). In most eyes, hypofluorescent lines were visible in the area of the graft (Figure $3 g$, early phase FA).

Complications of surgery included intraoperative bleeding, postoperative development of fibrosis, and macular pucker formation. In two eyes, persistent macular holes were seen after silicone oil removal surgery.

\section{Discussion}

In this report, we analyse the morphology of the graft and the overlying retina after a free transplant of choroid and RPE in patients with AMD.

OCT images demonstrate that the highly reflective band of the graft presumably corresponding to the RPE and the surrounding RPE layer appear as one continuous red band as early as 3 weeks after surgery. Previous studies reported reperfusion of the graft visible on indocyanin green angiography 3 weeks postoperative as well as early recovery of visual acuity in patients after graft surgery. ${ }^{13,14}$ Accordingly it might be speculated, although it could only be proven with histology, that the graft is integrated into the surrounding RPE choroidal complex early after surgery. Interestingly, a disconnection between graft and recipient RPE apparent on single OCT scans (Figure $3 a$ and b) was not associated with recurrent $\mathrm{CNV}$ formation in our series. It cannot be proven without histology that the gap between both RPE bands seen in single OCT scans is not only simulated by shadowing from overlying structures but may also exist and be missed during the imaging procedure because they are not cut by one of the six OCT scans.

Few weeks after surgery, the patch appeared more or less prominent in most cases. Grafting results, at least in part, in a double sandwich-like structure with the underlying recipient choroid, Bruch's membrane, and RPE covered by the full thickness graft consisting of donor-RPE, Bruch's membrane, and donor choroid. Additionally, fluid due to intraoperative trauma and irritation may accumulate in the grafted tissue. During follow-up, flattening of the patch was visible in most cases (Figure 1).

At 6-months follow-up, there was a moderate correlation between thickness of the graft and far visual acuity ( $r=0.46, P=0.01$ ); however, there was no correlation with reading vision. The reason for the worse functional outcome in eyes with prominent grafts is yet unknown. In our series, we found no correlation with development of fibrosis, macular pucker formation, or vascularisation pattern.

On OCT scans, two high-reflective bands can be distinguished in the area of the graft in several patients (Figure $3 c-f)$. Although it is likely that after graft surgery the upper band reflects the RPE layer of the graft, it seems possible that the lower high-reflective band represents blood vessels of the graft. The presence of dilated, large calibre choroidal vessels is reported in a study analysing histological findings after translocation of RPE and choroid in a pig model. ${ }^{24}$

Although histology would be needed to assign the different hypo- and hyper-reflecting layers of the graft visible on OCT with certainty to specific anatomic structures, OCT is of prominent value for determination of intraretinal fluid and oedema and is of increasing interest for monitoring treatment effects of different therapies. ${ }^{25-28}$ In our series, maximum retinal thickness decreased from mean $408 \pm 127 \mu$ m preoperative to mean $373 \pm 104 \mu \mathrm{m}$ at 6 -month follow-up; however, this was not statistically significant $(P=0.094)$. A late macular oedema is described to be a frequent complication after macular translocation surgery or pigment cell transplantation. ${ }^{7,10}$ In our series, one patient with geographic atrophy showed delayed vascularisation of the graft and increasing macular oedema after 3 months (Figure 4). Two eyes showed macular oedema at 6-month follow-up due to epiretinal membrane formation. Despite this, so far no late macular oedema has been observed.

The reduction of retinal thickness is commonly used as a morphological outcome parameter after treatment, but interestingly does not necessarily correlate with functional benefit. ${ }^{29,30}$ In our study, eyes with normal retinal appearance reached better distant visual acuity than eyes with retinal oedema, atrophy, or mixed appearance of the retina; however, this was not statistically significant. Our findings indicate that a functional interaction between photoreceptors and functioning graft-RPE is possible after graft translocation, and in turn may lead to a normalisation of the covering retina. Even several eyes with atrophic or oedematous retina showed functional stabilisation or improvement.

Most eyes demonstrated lines of blocked fluorescence visible on fluorescein angiography that correlated with hyperpigmented lines upon funduscopy. These hypofluorescent lines presumably represent pleats of the RPE layer. In seven eyes without macular oedema on OCT, hyperfluorescent areas were visible in mid and late phase of fluorescein angiography. Presumptions that this hyperfluorescence is at least partially explained by RPE disturbance seem possible, but may eventually indicate 
leakage of newly formed or reperfused vessels of the graft, or more likely in the absence of retinal oedema and subretinal fluid represent the staining of graft tissue.

Metamorphopsia is a common symptom in patients with AMD. Interestingly, although the graft appeared prominent or wrinkled, most patients did not complain about disturbing metamorphopsia, which were more frequently present in eyes with fibrosis or macular hole formation. This phenomenon has also been described in patients with PED. ${ }^{31}$ In our series, the lack of metamorphopsia in some patients might be explained by reduced visual acuity. However, $90 \%$ of the eyes with visual acuity better than 1.6 and central fixation did not complain about metamorphopsia.

In conclusion, this study indicates that a normal retinal morphology can be achieved after graft surgery. Flat appearance of the graft seems to be an important factor to achieve good functional results. However, being limited by the small number of patients; however, there was no statistically significant correlation between retinal configuration and functional outcome. Interpretation of OCT scans in this study is limited because of the lack of histological correlation.

These data identify OCT as a valuable diagnostic tool for eyes after surgery for AMD and as a supplement to angiographic evaluation. Further improvements in visualisation of intra- and subretinal morphology, ${ }^{32-34}$ advances in the understanding of anatomic correlates as well as refinements of measurements ${ }^{35,36}$ are anticipated and may enhance the analysis of retinal images in clinical trials.

\section{Acknowledgements}

We thank Beate Prinz and Erica Menrath for expert technical assistance. This work was supported by DFG Jo 324/6-2 (Emmy Noether) and DFG Ki 743/5-1.

\section{References}

1 Bressler NM, Bressler SB, Congdon NG, Ferris III FL, Friedman DS, Klein R et al. Age-related eye disease study research group. Potential public health impact of agerelated eye disease study results: AREDS report no. 11. Arch Ophthalmol 2003; 121: 1621-1624.

2 Pauleikhoff D. Neovascular age-related macular degeneration: natural history and treatment outcomes. Retina 2005; 25: 1065-1084.

3 Gragoudas ES, Adamis AP, Cunningham ET, Feinsod M, Guyer DR. VEGF inhibition study in ocular neovascularization. Pegaptanib for neovascular age-related macular degeneration. N Engl J Med 2004; 351: 2805-2816.

4 TAP Study Group: Treatment of Age-related Macular Degeneration with Photodynamic Therapy (TAP) Study Group. Photodynamic therapy of subfoveal choroidal neovascularization in age-related macular degeneration with verteporfin. One year results of 2 randomized clinical trials - TAP Report 1. Arch Ophthalmol 1999; 117: 1329-1345.

5 Verteporfin in Photodynamic Therapy Study Group. Verteporfin therapy of subfoveal choroidal neovascularization in age-related macular degeneration: two-year results of a randomized clinical trial including lesions with occult with no classic choroidal neovascularization - verteporfin in photodynamic therapy report 2. Am J Ophthalmol 2001; 131: 541-560.

6 Submacular Surgery Trial Research Group. Surgery for subfoveal choroidal neovascularization in age-realted macular degeneration. Ophthalmic findings: SST Report no. 11. Opthalmology 2004; 111: 1967-1980.

7 Binder S, Krebs I, Hilgers RD, Abri A, Stolba U, Assadoulina A et al. Outcome of transplantation of autologous retinal pigment epithelium in age-related macular degeneration: a prospective trial. Invest Ophthalmol Vis Sci 2004; 45: 41514160 .

8 Eckardt C, Eckardt U. Macular translocation in nonexudative age-related macular degeneration. Retina 2002; 22: 786-794.

9 Cahill MT, Freedman SF, Toth CA. Macular translocation with 360 degrees peripheral retinectomy for geographic atrophy. Arch Ophthalmol 2003; 121: 132-133.

10 Terasaki H, Ishikawa K, Suzuki T, Nakamura M, Miyake K, Miyake Y. Morphologic and angiographic assessment of the macula after macular translocation surgery with 360 degrees retinotomy. Ophthalmology 2003; 110: 2403-2408.

11 Park CH, Toth CA. Macular translocation surgery with 360degree peripheral retinectomy following ocular photodynamic therapy of choroidal neovascularization. Am J Ophthalmol 2003; 136: 830-835.

12 Khurana RN, Fujii GY, Walsh AC, Humayun MS, de Juan Jr E, Sadda SR. Rapid recurrence of geographic atrophy after full macular translocation for nonexudative age-related macular degeneration. Ophthalmology 2005; 112: 1586-1591.

13 Joussen AM, Heussen FMA, Joeres S, Llacer H, Prinz B, Rohrschneider $\mathrm{K}$ et al. Autologous translocation of the choroid and rpe in age related macular degeneration - six month follow-up in 45 patients. Am J Ophthalmol 2006; 142: $17-30$.

14 Joussen AM, Joeres S, Fawzy N, Heussen FMA, Llacer H, van Meurs JC et al. Autologous translocation of the choroid and rpe in patients with geographic atrophy. Ophthalmology 2006 (in press)

15 Van Meurs JC, Van Den Biesen PR. Autologous retinal pigment epithelium and choroid translocation in patients with exudative age-related macular degeneration: shortterm follow-up. Am J Ophthalmol 2003; 136: 688-695.

16 Fukuchi T, Takahashi K, Uyama M, Matsumura M. Comparative study of experimental choroidal neovascularization by optical coherence tomography and histopathology. Jpn J Ophthalmol 2001; 45: 252-258.

17 Toth CA, Narayan DG, Boppart SA, Hee MR, Fujimoto JG, Birngruber $\mathrm{R}$ et al. A comparison of retinal morphology viewed by optical coherence tomography and by light microscopy. Arch Ophthalmol 1997; 115: 1425-1428.

18 Hee MR, Puliafito CA, Wong C, Reichel E, Duker JS, Schuman JS et al. Optical coherence tomography of central serous chorioretinopathy. Am J Ophthalmol 1995; 120: 65-74.

19 Montero JA, Ruiz-Moreno JM, Tavolato M. Follow-up of age-related macular degeneration patients treated by photodynamic therapy with optical coherence tomography 3. Graefes Arch Clin Exp Ophthalmol 2003; 241: 797-802. 
20 Puliafito CA, Hee MR, Lin CP, Reichel E, Schuman JS, Duker JS et al. Imaging of macular diseases with optical coherence tomography. Ophthalmology 1995; 102: 217-229.

21 Gallemore RP, Jumper JM, McCuen II BW, Jaffe GJ, Postel EA, Toth CA. Diagnosis of vitreoretinal adhesions in macular disease with optical coherence tomography. Retina 2000; 20(2): 115-120.

22 Stifter E, Konig F, Lang T, Bauer P, Richter-Muksch S, Velikay-Parel $\mathrm{M}$ et al. Reliability of a standardized reading chart system: variance component analysis, test-retest and inter-chart reliability. Graefes Arch Clin Exp Ophthalmol 2004; 242: 31-39.

23 Radner W, Willinger U, Obermayer W, Mudrich C, Velikay-Parel M, Eisenwort B. Eine neue lesetafel zur gleichzeitigen bestimmung von lesevisus und lesegeschwindigkeit. Klin Monatsbl Augenheilkd 1998; 213: 174-181.

24 Maaijwee KJM, van Meurs JC, Kirchhof B, Mooij NM, Mackiewicz J, Kobuch $\mathrm{K}$ et al. Histological evidence for revascularization of an autologous RPE-choroid graft in the pig. Br J Ophthalmology 2006 (in press).

25 Costa RA, Farah ME, Cardillo JA, Calucci D, Williams GA. Immediate indocyanine green angiography and optical coherence tomography evaluation after photodynamic therapy for subfoveal choroidal neovascularization. Retina 2003; 23(2): 159-165.

26 Rogers AH, Martidis A, Greenberg PB, Puliafito CA. Optical coherence tomography findings following photodynamic therapy of choroidal neovascularization. Am J Ophthalmol 2002; 134: 566-576.

27 Sahni J, Stanga P, Wong D, Harding S. Optical coherence tomography in photodynamic therapy for subfoveal choroidal neovascularization secondary to age related macular degeneration: a cross sectional study. $\mathrm{Br} J$ Ophthalmol 2005; 89: 316-320.
28 Krebs I, Binder S, Stolba U. A new treatment regimen in combined intravitreal injection of triamcinolone acetonide and photodynamic therapy. Graefes Arch Clin Exp Ophthalmol 2006; 244: 863-867.

29 Massin P, Duguid G, Erginay A, Haouchine B, Gaudric A. Optical coherence tomography for evaluating diabetic macular edema before and after vitrectomy. Am J Ophthalmol 2003; 135: 169-177.

30 Otani T, Kishi S, Maruyama Y. Patterns of diabetic macular edema with optical coherence tomography. Am J Ophthalmol 1999; 127: 688-693.

31 Roquet W, Roudot-Thoraval F, Coscas G, Soubrane G. Clinical features of drusenoid pigment epithelial detachment in age related macular degeneration. $\mathrm{Br} J$ Ophthalmol 2004; 88: 638-642.

32 Ko TH, Fujimoto JG, Schuman JS, Paunescu LA, Kowalevicz AM, Hartl I et al. Comparison of ultrahigh- and standardresolution optical coherence tomography for imaging macular pathology. Ophthalmology 2005; 112: 1922.

33 Schmidt-Erfurth U, Leitgeb RA, Michels S, Povazay B, Sacu $\mathrm{S}$, Hermann B et al. Three-dimensional ultrahigh-resolution optical coherence tomography of macular diseases. Invest Ophthalmol Vis Sci 2005; 46: 3393-3402.

34 Hermann B, Fernandez EJ, Unterhuber A, Sattmann H, Fercher AF, Drexler W et al. Adaptive-optics ultrahighresolution optical coherence tomography. Opt Lett. 2004; 29: 2142-2144.

35 Sadda SR, Wu Z, Walsh AC, Richine L, Dougall J, Cortez R et al. Errors in retinal thickness measurements obtained by optical coherence tomography. Ophthalmology 2006; 113: 285-293.

36 Sadda SR, Joeres S, Wu Z, Romano P, Collins AT, Walsh AC. Error correction and quantitative sub-analysis of optical coherence tomography data using computer-assisted grading. Invest Ophthalmol Vis Sci 2006; 48: 839-848. 